\title{
Adolescent construction of mental illness: implication for engagement and treatment
}

Katharine Chisholm ${ }^{*}$, Paul Patterson ${ }^{2}$, Sheila Greenfield ${ }^{3}$, Erin Turner ${ }^{4}$, Max Birchwood $^{1}$

${ }^{1}$ School of Psychology, University of Birmingham, Edgbaston, Birmingham, B15 2TT, UK.

${ }^{2}$ Youth Programme, Birmingham \& Solihull Mental Health Foundation Trust, Research \& Innovation, 68 Hagley Road, Birmingham B16 8PF, UK.

${ }^{3}$ School of Health \& Population Sciences, College of Medical and Dental Sciences, University of Birmingham, Birmingham B15 2TT, UK.

${ }^{4}$ Early Intervention Services, Birmingham and Solihull Mental Health Foundation Trust, Newington Resource Centre, Newington Road, Marston Green, Birmingham, B37 7RW, UK.

* corresponding author. School of Psychology, University of Birmingham, Edgbaston, Birmingham, B15 2TT, UK. K.e.chisholm.1@bham.ac.uk 01214146241

\section{Acknowledgements}

We would like to thank the participants, teachers and schools for taking the time to be part of this project.

The authors were funded by the National Institute for Health Research (NIHR) through the Collaborations for Leadership in Applied Health Research and Care for Birmingham and Black Country (CLAHRC-BBC) programme. The views expressed in this publication are not necessarily those of the NIHR, the University of Birmingham or the CLAHRC-BBC Theme 3 Management.

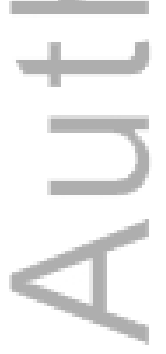

This is the author manuscript accepted for publication and has undergone full peer review but has not been through the copyediting, typesetting, pagination and proofreading process, which may lead to differences between this version and the Version of Record. Please cite this article as doi: 10.1111/eip.12347

This article is protected by copyright. All rights reserved. 


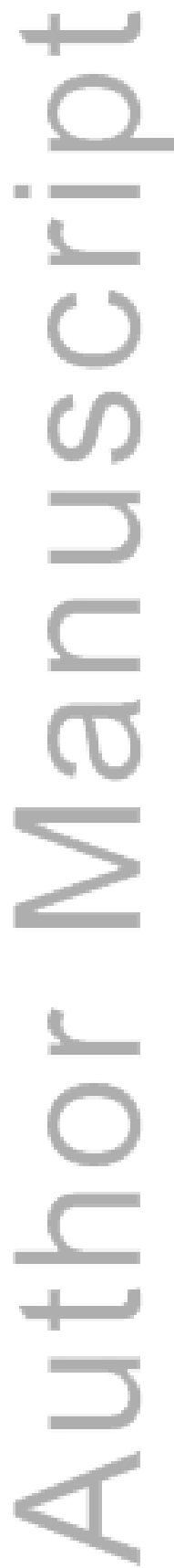

This article is protected by copyright. All rights reserved. 


\section{ABSTRACT:}

Aims: Understanding how adolescents perceive mental illness is important for clinicians wishing to improve engagement, and for the development of educational programmes and health-behaviour directed policies. The current research aimed to develop a preliminary model of how adolescents perceive mental illness and construct their understanding of mental health.

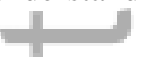

Method: 46 participants aged 11-18 from 6 schools in Birmingham, UK, took part in one of 12 group interviews.

Results: A thematic analysis highlighted a dual perception of mental illness. Adolescents discussed stereotypes and extreme examples of illness, but also displayed an insightful understanding of mental distress which had developed through participants' own experiences. Participants attempted to reconcile and negotiate these conflicting perceptions by creating distinctions between concepts of 'craziness' and 'normality', and reported experiencing negative emotions relating to both perceptions of illness.

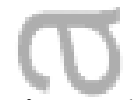

Conclusions: The findings suggest that once media stereotypes have been acknowledged, adolescents demonstrate a relatively sophisticated understanding of mental illness, although one which differed at times from the diagnostic medical model of mental illness. Focusing on individual symptoms, prevalence rates, and prior contact adolescents have had with individuals with mental illnesses provides a framework to discuss mental health and ill-health with adolescents.

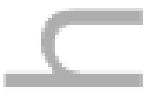

Keywords: adolescence, lay understanding, mental health, stereotypes, stigma

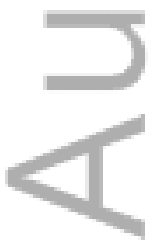




\section{INTRODUCTION:}

Policy documents cite child and adolescent mental health as a major target for research and clinical practice (1,

2). Over two thirds of all lifetime mental disorders onset prior to age 24 (3), with adolescence a particularly vital time for initiation of early detection and intervention. Despite this, adolescents are less likely to help-seek for mental health difficulties than adults (4).

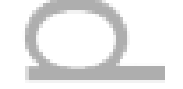

Lay and professional views of mental health may differ and health promotion initiatives must take this into account (5), yet little research has been conducted which seeks to develop an in depth qualitative understanding of how adolescents from the general population construct their understanding of mental health (6). The small amount of existing qualitative literature suggests that young people use their own emotional experiences to reflect on whether an individual may be experiencing a mental illness (6). Mental health may be viewed both in terms of positive and negative emotional experiences (7), however symptoms of mental illnesses are often classified as weird, rare, untreatable, or voluntary (8). Mental health awareness develops throughout childhood and adolescence, starting with initial perceptions of mental illness which are formed into a fully developed conception of mental health over time $(9,10)$. Understanding this process has implications for clinical strategies and enables professionals to frame and discuss mental illness in accessible terminology. Adolescents' willingness to listen to advice, answer questions and provide personal information, particularly under the shadow of stigma associated with mental illness, can be problematic (11) and adolescents may be more likely to engage with professionals who are capable of reflecting on the adolescent's own concept of mental health, and using examples which relate to adolescents' own perceptions of mental illness. This paper aims to develop a preliminary model of how adolescents perceive mental illness and construct their understanding of mental health.

\section{METHOD}

Data collection took place via semi-structured group interviews of 2-5 participants (Table 1). Group interviews are discussed by Benner (12) as grouping 2-5 individuals together in a safe space that encourages dialogue which might be lost in a larger focus group. The decision to conduct smaller group interviews, rather than larger focus groups, meant that participants were given space to consider and clarify their own viewpoints but were also able to bounce ideas off each other as they would in a larger focus group (13). Although this discussion was 
allowed to naturally occur, no emphasis was placed on group discussion over the voicing of individual view points, and the interviewer directed questions so as to allow each participant adequate opportunity to express their opinions. Due to the potential for being viewed as a mental health 'expert' by participants, the researcher maintained a passive role during the data collection, guiding the focus of the interviews, but retaining a neutral presence.

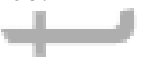

\section{Sampling}

Seven schools that had expressed an interest in taking part in a related project $(14,15)$ were approached. All seven agreed to participate, but one later declined due to timetabling pressures. Schools were selected to be broadly representative of Birmingham, UK (Table 2). A topic guide was piloted with one school, and this resulted in the inclusion of engagement strategies (Table 3;16). Participants and their parents gave informed consent prior to taking part in the study. The study was granted ethical approval by The University of Birmingham ethics committee. All interviews were conducted by KC. Locations of interviews can be viewed in table 4.

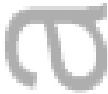

46 participants took part in one of 12 group interviews (Table 4), each lasting 40 minutes. Data collection continued until saturation was reached (i.e. conducting new interviews was no longer found to develop existing themes further; 17). Teachers were asked to select a range of students from the students who had volunteered for the study. Teachers were asked to select friendship groups so that students felt comfortable speaking in front of each other, and were asked to select a range of groups which accurately reflected the students at the school. To reduce teacher bias (e.g. selecting students who would represent the school in a positive light) teachers were assured that school identities would remain confidential.

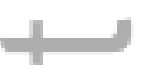

No other screening or assessment took place prior to the research regarding students' knowledge, attitudes, or previous exposure to mental illness. Participants were informed that the research was to find out what they thought about mental health. Participants were left to themselves to discuss and define what they felt this term might mean. Gender differences in students' emotional needs (18) and reported difficulties for adolescents discussing sensitive topics with members of the opposite sex (19) led to a decision to facilitate single gender groups. 


\section{Analysis}

Interviews were recorded and transcribed verbatim. A thematic analysis process was used (20). Analysis and data collection coincided so that themes identified in earlier interviews could be explored more fully in later ones (21). Data analysis took place as an inductive process where no attempt was made to fit the data into a preexisting model. Reflexive memo writing and constant comparative methods were employed (22). Negative case analysis was used to check that themes accurately represented the data. This involved searching the data for cases which did not support emerging themes, and then refining, revising, or broadening themes in order to incorporate and recognise these 'negative cases' (23). To lessen the impact of researcher bias three of the authors (KC, PP, and $\mathrm{SG})$ independently read 4 transcripts and the emerging themes were discussed to develop a thematic coding framework used by $\mathrm{KC}$ to code each transcript systematically. There was general agreement between the 3 authors in the identification of themes. Any discrepancies were discussed and agreement negotiated.

\section{RESULTS}

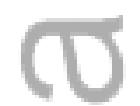

Four overarching themes were developed from the data; Perceptions of mental illness, Seeking help, Adolescent development, and Information and knowledge. This paper focuses on Perceptions of mental illness, which reflects the adolescents' conflicting experiences and perceptions of mental illness.

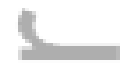

A dual perception of mental illness was found; participants discussed Stereotypes and Extreme symptoms of mental illness, but also displayed an insightful and empathetic understanding of the negative impact of stress, based on their own Reality and experiences. Attempting to make sense of this dual understanding, participants created a distinction between individuals who are 'different' and those who are 'normal'; examined in the theme Normality and Difference. Emotions of Fear and anxiety were associated with both perceptions. Participants have been given pseudonyms. Themes and subthemes are highlighted with italics. Full quotes illustrating each theme can be seen in table 5 .

\section{Stereotypes and extremes}

Highlighting how stereotypes and extreme examples of mental disorder permeated perceptions of mental illness, the predominant response and initial reaction from the majority of participants to the question "what does mental 
health mean to you?' was associated with common negative stereotypes and notions of extreme illness.

Symptoms, behaviours, and treatments were mentioned, with individuals who experience mental disorders presented as aggressive, unpredictable, and out of control. The extent to which some participants endorsed this viewpoint was displayed by comments stating that they would discontinue a friendship (G5 11-12 year old males) or call the police (G4 11-12 year old males) if they found out a friend had a mental illness. Stereotypes were present even for participants with personal experience of mental illness. For example, despite disclosing personal experience of mental illness, Andy's initial thoughts when discussing mental health related to themes of craziness; 'mental health would be associated with crazy people' (G9 16-18 year old males).

Many participants had come into contact with individuals exhibiting behaviours which they had classified as crazy, and these personal negative experiences added to the stereotype of mental illness. These experiences often had not been discussed outside the peer group, leading to a view of mental illness that was at times onesided; for many participants, individuals exhibiting odd or bizarre behaviours had come to represent what mental illness meant to them, even though under some circumstances the behaviour they described could potentially be differently attributed, for example to inebriation. In a vacuum of school or public health education regarding the symptoms of mental disorder the man 'screaming at us' in the street (G6 13 -14 year old females) had come to represent what they believed mental illness might be. Pop-culture stereotypes of madness fed into this understanding, with a few participants describing childhood cartoons as their first introduction to stereotypes of mental illness; 'I think it was buggs bunny I don't know why but um I thought that he like had mental illness' (G2 11-12 year old females). The participants were also reflective however, regarding their level of uncertainty around the construct of mental illness, and displayed an awareness of the relationship between stereotypes and media representations.

Jon: That always, like, makes it worse, for like, for people who do have mental health problems, because all the news that you see is, like, bad.

Eli: Yeah. The only contact people really have is with is with the criminals.

G7 15-16 year old males

Participants also displayed a sophisticated understanding of the stigma to which negative stereotypes can lead. Participants were keenly aware of playground jokes and bullying, and of how media concepts of 'madness' fed 
into this. Participants' discussed that the words 'mental illness' might mean something different in reality to the stereotypical way in which western society often uses them.

Amy: in films people portray it as someone whose gone crazy or something whereas if you actually had them yourself you may not actually be like that

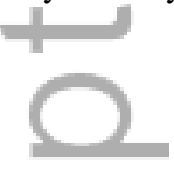

G1 11-12 year old females

Reality

In direct contrast to perceptions of Stereotypes and Extremes were perceptions which related to the participants' understanding of mental distress, including their own emotional experiences as well as the experiences of those closest to them. These experiences had increased understanding and enabled them to 'empathise' (G9 16-18 year old boys).

Jess: my mum's friend's got bi-polar and I thought all schizophrenics and people with bi-polar are gonna be absolutely mental, but I think my opinion changed

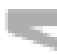

G12 16-18 year old females

A significant subset of the participants had friends or family who had experienced mental illnesses, with more older than younger participants reporting experiences with friends. This kind of personal contact with individuals with mental illness led away from perceptions that mental illness was something that only happened to people who were 'different' or innately 'crazy' and had therefore helped to reduce levels of stigma and stereotypical viewpoints of mental illness. By discussing causes of mental illness participants moved away from a categorical 'them and us' or 'born with it' perspective to perceiving mental illness as something which an individual could develop and recover from. Similarly, it was when considering themselves and those they knew that participants, particularly those in the older age groups, discussed mental health in a positive sense relating to emotional well-being as opposed to using the term 'mental health' to mean 'mental illness'.

Debbie: I think it's good to have really good mental health but everyone has traits of something. 
Related to perceptions of development and recovery, the participants interpreted mental health and ill-health as a continuum, rather than just focusing on the extreme examples. This related to; type and severity of mental illnesses; ‘some people could just have like a mild version' (G11 16-18 year old females); everyday stress and the effect this has on emotional health; 'you're so stressed you don't think straight' (G6 13-14 year old females); and individual personality quirks or traits. With this more inclusive perspective mental illness was seen as relevant and as something which could potentially happen to the participants themselves. Participants also discussed prevalence levels and this perspective helped to reduce stigma, as participants discussed that the high prevalence levels meant that it was possible that they or their loved ones could possibly develop a mental illness. This in turn reduced notions of 'them and us' and the idea that individuals with mental illnesses were 'different' or 'not normal'.

$$
\text { in }
$$

Ryan: They can say "why have you got mental problems”. They can't help it bla bla bla. If you take the mick out of them, then how do you know, how do you know you might not get mental problems when you're older.

$\mathrm{KC}: \mathrm{mmm}$

Si: Yeah but kids aren't like that in this school are they?

Ryan: Yeah but that's this school. What about other schools?

KC: Do you think kids in other schools might have mental health problems?

Ryan: Yeah loads of kids, all around the world.

G4 11-12 year old males

\section{Normality and difference}

The two perceptions of mental illness, Stereotypes and Extremes of 'craziness' and the Reality of experiences of mental ill-health, provided a messy and often conflicting picture of mental illness which participants attempted to reconcile. Distinctions were drawn; between 'them' and 'us', between 'born with it' and 'developed', and between 'crazy' and 'diagnosed'. The distinction 'them' and 'us' emerged early in the interviews, and the idea that those with mental disorders were somehow 'not normal' or 'different' was revisited often by participants. This difference was seen as long term and contrasted with the idea of the mental health continuum discussed in the theme of Reality. 
A distinction between the idea that some are born with a mental illness, whereas others may develop mental health problems also emerged. The perception of mental illness discussed in the Stereotypes and Extremes theme was often not conceived as something that could develop, but as something one was 'born with'. This reduced levels of blame associated with mental illness 'if they're born with it, they can't help it' (G4 11-12 year old males), however it also increased the distinction participants made between 'them and us'. One interesting outcome of this was a rift between the idea of 'craziness' and the diagnoses which the young people were aware of; where the participants had knowledge about a particular diagnosis and knew that individuals could both develop and recover from it, instead of reconceptualising their understanding of mental illness they instead had often reclassified these disorders as something other than mental illness. This led to an interesting distinction drawn between the stereotyped view of mental health, and many common disorders.

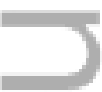

Will: it just doesn't sound like a mental illness because you weren't born depressed

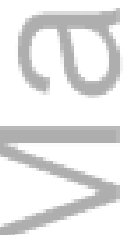

G9 16 - 18 year old males

Jenny: mental health is crazy, and depression, bipolar, anorexia, bulimia, they're all like, they're all a different category

Danielle: I wouldn't like I never used to class them with mental health like, if you're crazy you're mental, and the others you're like ill

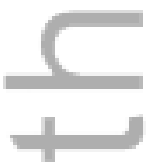

G6 13-14 year old females

Fear

Emotions of anxiety and Fear were associated with both themes of Stereotypes and Extremes and of Reality. Associations between Fear and themes of Stereotypes and Extremes were particularly prevalent for the younger participants; 'if there was someone mental in this school you'd be scared' (G4 11-12 year old males). Related to the theme of Reality were concerns regarding mental illness in friends and family, as well as a fear of developing a mental illness; 'I was scared by it, if it would happen to me or not' (G2 11-12 year old females). Often, this was related to a feeling that developing a mental illness was predestined and entirely out of their control, a 
perception which relates to the Normality and Difference subtheme that some individuals with mental disorders are 'born with it'; this 'innate' quality of illness was associated with a perception of 'helplessness' in the face of its expression.

Mental illness affecting friends and family also caused worry, sometimes developing into a major focus of anxiety in participants lives. More than half of the participants discussed peers with mental disorders, and many reported feeling ill-equipped to deal with the emotional pressure which this sometimes entailed.

Rupa: the way she was talking as well, like she was going to do something, like she was going to overdose again or something like that and it was really scary because it was like, what, like I can't sit in class and just think she will be okay because she is gonna be alone at home she could do anything

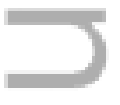

G11 16-18 year old females

Such apprehensions, of individuals with mental disorders, of developing a mental illness, and of supporting friends in mental distress, were ameliorated for those young people who felt that they were equipped to deal with such situations by having the knowledge to cope. By contrast, these situations were often seen as satisfying or rewarding.

Jessica: I mean, obviously you're always a bit nervous about like things that do happen to someone and you don't want them to happen to you, but at the same time they don't scare me as much because I realise that they can be sorted out and, and so they don't seem as scary

G2 11-12 year old females

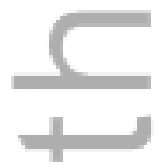

Kareem: he was telling me about times where he's feeling suicidal and he was thinking about times when he wanted to cut himself and when he wanted to hit people, even if they were boys or girls... Um, so... I guess I just, well, I kind of, like I did feel kind of, erm, satisfied that I was actually able to have a conversation with him.

G7 15-16 year old males 


\section{DISCUSSION}

The adolescents described a dual perception of mental illness. The first of these revolved around stereotyped images of 'craziness' and focused on extreme examples of illness. In contrast, although the participants initial reactions centred around stereotypes, their second perception displayed a relatively sophisticated understanding of emotional well-being and ill-health based upon the participants' own life experiences and the experiences of those closest to them, albeit an understanding which often differed from the diagnostic medical model, and instead focused on the impact of stress and negative emotions on well-being. Attempting to negotiate and reconcile these conflicting perceptions, a series of distinctions were made; between them and us, between born with and developed, and between crazy and diagnosed. The adolescents also discussed negative emotions which related to both perceptions; a fear of individuals with mental disorders, of developing a mental illness, and of lacking the ability or knowledge to help those they knew who experienced severe mental distress.

Previous quantitative research has suggested that adolescents hold relatively stigmatising attitudes toward mental illness (24-26). The present research amplifies this body of work by suggesting that although initial reactions from participants related to negative stereotypes, further discussion revealed this to be unrepresentative of the true level of understanding; participants were willing and able to engage in in-depth and insightful discussion regarding mental distress and from this 'Reality' perspective mental illness was conceived as relevant and prevalent. One possible reason for this contrast is that previous quantitative research is likely to have captured similar initial attitudes to mental illness, but missed the opinions participants subsequently expressed. Consistent with previous research (27), the media was commonly associated with the development of more discriminatory themes. The adolescents in this study reported that they were uncertain of media-promoted stereotypes, but that media representations were often a predominant source of information.

One interesting outcome from the distinctions which participants drew in the Normality and Difference theme was a conception of mental illness which differed from traditional medical models (27). Specific diagnoses mentioned included depression, OCD, bipolar, schizophrenia, anorexia, bulimia, autism, and dementia, with depression, schizophrenia, anorexia, and autism being the most commonly mentioned disorders. In general however specific diagnoses were not discussed in detail. Participants did not categorise disorders such as depression within the boundaries of mental illness. Instead, disorders were seen as part of an emotional continuum ranging from 'happiness' to 'distress', and an individual might travel this continuum, without ever 
presenting with a mental disorder. This is consistent with previous qualitative work within adult populations, which found that adults perceived depression as a normative element of human existence, rather than as a pathological illness (28), as well as qualitative work with adolescents which found that symptoms of mental illness which the adolescent participants could relate to were often not deemed to be a part of mental illness but were reclassified as a part of everyday life (6). Previous qualitative work with adolescents has reported that when asked about 'mental health' adolescents perceive it as an emotional experience involving positive and negative emotions (7). This is comparative to the theme of Reality in the present research where adolescents perceived mental health as a continuum which ran from emotional health through to ill-health. Maclean and colleague's (8) findings that symptoms of mental illness are viewed as weird, rare, untreatable, and voluntary are comparable to the views expressed within the Stereotypes and Extremes theme. The primary difference between this theme and Maclean and colleague's findings was the idea that mental illness was voluntary. In the current research, and linked to the 'born with it' narrative, mental illness was seen as something which was involuntary. The vast majority of research into fearful emotions in relation to mental illness has focused on fear of individuals who live with mental disorders (29), calling for an increase in mental health education to reduce perceptions of dangerousness (30). Whilst the present research found that adolescents reported fearful reactions to individuals who experience mental illness, fear and anxiety also related to the development of a mental illness, and having adequate skills and knowledge to support friends in crisis. This suggests that mental health education may have some potential to reduce fears associated with mental illness which are unrelated to perceptions of Stereotypes and Extremes. Older participants reported higher levels of contact with individuals who experienced mental disorders, and participants who discussed contact reported that this had enabled them to develop more understanding. This finding is consistent with previous research in the field of mental health literacy (31) which reports that contact can increase knowledge and reduce stigma (32). In general few differences in age were observed, the most notable being that a fear of individuals with mental health problems was reported more commonly in younger participants and discussed only occasionally by older participants.

It is possible that the stigma which surrounds mental health may have caused some suppression of participants' views due to the group interview format. The methodology however, allowed participants to 'bounce' ideas off each other and develop their opinions (13). This was particularly important as some participants reported never having discussed mental health topics before, however it means that the discussion reflected a synthesis of views rather than participant's individual viewpoint or primary opinion. The researcher attempted to maintain a 
passive role and did not contribute to group discussions beyond asking the questions listed in Table 1, asking for clarification of participants viewpoints, and encouraging participants who hadn't offered their opinion to speak if they wished to. Despite this it seems likely that the presence of an adult who was likely viewed as a mental health 'expert' by participants may have biased the content of the participants' discussion. It also needs to be acknowledged that, though chosen to come from a range of backgrounds, the adolescents who took part in the research are not representative of all adolescents. It is important that the research is placed with its context as capturing a snapshot of reality. This does not necessarily mean that the experiences of the adolescents who took part in this research are not reflective of the experiences of adolescents from elsewhere. The experiences which shaped the adolescents' perceptions were not specific to the UK; media influences (33), challenges to schoolbased mental health education (34), and rates of mental illness are similar in many westernised nations (35). Care was taken to minimise bias, through the research techniques outlined in the analysis section and including reflexive memo-writing, negative case analysis, and constant comparative method, which are common techniques to ensure validity and reliability in qualitative research. Quotes given enable the reader to develop an account of the trustworthiness of the data, and details are given regarding the participants who took part in the research allowing the reader to assess the generalizability of the research.

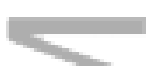

Very little prior research has investigated how adolescents from the general population conceptualise mental health. An accurate understanding of how adolescents perceive mental illness and interpret these perceptions to form conceptions of mental health is vital to inform stigma and discrimination research, policy decisions, and for the creation of appropriate educational and clinical resources. With adolescents' poor levels of help-seeking (4), a better understanding of how they perceive mental illness may enable the improvement of care pathways, for example through public health campaigns designed specifically for adolescent populations. The current research informs these areas in a number of ways. The study adds support to the growing body of research which advocates the use of contact with individuals who have lived experience of mental illness to reduce stigma (36) as participants reported that personal experiences with friends and family who had experienced mental illnesses had allowed them to develop their understanding of mental illness, and to view individuals with mental illnesses as 'normal' instead of 'different' or 'crazy'. It also has implications for health and education professionals involved in communicating with adolescents regarding mental illness; estimates suggest as many as one in two will experience a mental illness during their lifetime (37) and discussing with adolescents whether they know anyone with mental illness may help direct the conversation away from stereotypes (which was the 
predominant initial response when participants were first asked about mental health) and instead frame the conversation within the theme of 'reality' (which participants tended to consider more readily when thinking about individuals they knew who had experienced mental illnesses or high levels of distress). For clinicians working with adolescents experiencing mental illnesses, it is possible that discussing any prior contact they may have had with individuals who experience mental illness may help to reduce the negative impact of self-stigma.

Public mental health and anti-stigma campaigns may also be more effective if discrete disorders or symptoms are targeted, rather than more generic terms such as 'mental illness'. Participants in the present study drew strong links between the term mental illness and derogatory terms such as 'crazy', but were less stigmatising regarding individual diagnoses. The current research also highlights the importance of including environmental or 'biopsychosocial' explanations of mental illness rather than only biological explanations (36) which may confer themes of 'born with it', which in turn were linked to conceptions of 'craziness'. Adolescents in the present study were also more able to conceive of mental illness as relevant to them from this more holistic viewpoint. The 'born with it' narrative and it's links to negative stereotypes of mental illness is reflective of literature within adult populations which note that as biological explanations of mental illness become more prevalent within cultural understanding of mental illness, stigma trends have remained the same or worsened $(38,39)$, with a recent meta-analysis reporting that biogenetic explanations of mental illness reduced blame but increased pessimism relating to recovery (40). When discussing mental health with adolescents it may be preferable for clinicians to discuss specific disorders rather than using the more generic term of mental illness, as this may increase adolescents' fear of 'becoming crazy'. By contrast, disorders were seen as something which an individual could develop, and importantly, recover from, and therefore may be more acceptable to young people seeking help or advice from health professionals.

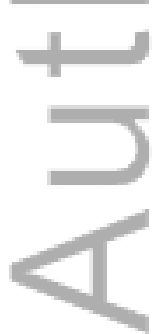




\section{REFERENCES}

1. Royal College of Psychiatrists. No Health Without Public Mental Health; the case for action. 2010.

2. DoH. No Health Without Public Mental Health: Implementation Framework. 20122012. Report No.

3. Kessler RC, Berglund P, Demler O, Jin R, Walters EE. Lifetime prevalence and age-of-onset distributions' of DSM-IV disorders in the national comorbidity survey replication. Archives of General Psychiatry. 2005;62(6):593-602.

4. Collins KA, Westra HA, Dozois DJA, Burns DD. Gaps in accessing treatment for anxiety and depression: Challenges for the delivery of care. Clinical Psychology Review. 2004;24(5):583-616.

5. = Who. Promoting Mental Health: Concepts - Emerging Evidence - Practice. World Health Organisation, 2005.

6. Secker J, Armstrong C, Hill M. Young people's understanding of mental illness. Health Education Research. 1999;14(6):729-39.

7. Johansson A, Brunnberg E, Eriksson C. Adolescent girls' and boys' perceptions of mental health. Journal of Youth Studies. 2007;10(2):183-202.

8. MacLean A, Hunt K, Sweeting H. Symptoms of mental health problems: Children's and adolescents' understandings and implications for gender differences in help seeking. Children \& society. 2013;27(3):161-73.

9. Flavell JH, Miller PH, Miller SA. Cognitive development. 4th ed. Upper Saddle River, NJ: Prentice-Hall; 20012001.

10. Corrigan PW, Watson AC. How children stigmatize people with mental illness. International Journal of Social Psychiatry. 2007;53(6):526-46.

11. Yap MB, Wright A, Jorm AF. The influence of stigma on young people's help-seeking intentions and beliefs about the helpfulness of various sources of help. Social Psychiatry and Psychiatric Epidemiology. 2011;46(12):1257-65.

12. Benner P. Interpretive phenomenology: Embodiment, caring, and ethics in health and illness: Sage publications; 1994.

13. Kitzinger J. Qualitative Research - Introducing Focus Groups. British Medical Journal. 1995;311(7000):299-302.

14. Chisholm KE, Patterson P, Torgerson C, Turner E, Birchwood M. A randomised controlled feasibility trial for an educational school-based mental health intervention: study protocol. Bmc Psychiatry. 2012;12:23.

15. Chisholm K, Patterson, P., Torgerson, C., Turner, E., Jenkinson, D., and Birchwood, M. The impact of contact on adolescents' mental health literacy and stigma: The SchoolSpace Cluster Randomised Controlled Trial. BMJ Open. 2016;IN PRESS.

16. Gibson F. Conducting focus groups with children and young people: Strategies for success. Journal of Research in Nursing. 2007;12:473-83.

17. Seale C. Grounding Theory. In: Seale C, editor. The Quality of Qualitative Research. London: SAGE Publications Ltd; 1999. p. 87-105.

18. Hjemdal O, Vogel PA, Solem S, Hagen K, Stiles TC. The Relationship between Resilience and Levels of Anxiety, Depression, and Obsessive-Compulsive Symptoms in Adolescents. Clinical Psychology \& Psychotherapy. 2011;18(4):314-21.

19. Strange $V$, Oakley A, Forrest S. Mixed-sex or single-sex sex education: how would young people like their sex education and why? Gender and Education. 2003;15(2):201-14.

20. Braun V, Clarke V. Using thematic analysis in psychology. Qualitative research in psychology. 2006;3(2):77-101.

21. Britten N, Jones R, Murphy E, Stacy R. Qualitative research methods in general practice: Oxford University Press; 19951995. 
22. Glaser BG, Strauss AL. The discovery of grounded theory: strategies for qualitative research. New York: Aldine de Gruyter; 19991999.

23. Onwuegbuzie AJ, Leech NL. Validity and qualitative research: An oxymoron? Quality \& Quantity. 2007;41(2):233-49.

24. SM S. The Second National Public Attitudes Survey, 'Well? What do you think?'. Edinburgh: 2004 2004. Report No.

25. Barney LJ, Griffiths KM, Jorm AF, Christensen H. Stigma about depression and its impact on help-seeking intentions. Australian and New Zealand Journal of Psychiatry. 2006;40(1):51-4.

26. Stuart H, Arboleda-Florez J. Community attitudes toward people with schizophrenia. Canadian Journal of Psychiatry-Revue Canadienne de Psychiatrie. 2001;46(3):245-52.

27. Morgan AJ, Jorm AF. Recall of news stories about mental illness by Australian youth: associations with help-seeking attitudes and stigma. Australian and New Zealand Journal of Psychiatry. 2009;43(9):866-72.

28. Hogg C. 'Your good days and your bad days' An exploration and consideration of how lay people conceptualize depression. Journal of psychiatric and mental health nursing. 2011;18(10):85161.

29. Fresan Orellana A, Robles Garcia R, Martinez Lopez N, Vargas-Huicochea I, Berlanga Cisneros C. Literacy among medical students on schizophrenia. Salud I Ciencia. 2012;19(3):220-3.

30. Reavley NJ, Jorm AF. Stigmatising attitudes towards people with mental disorders: Changes in Australia over 8 years. Psychiatry Research. 2012;197(3):302-6.

31. Jorm AF, Korten AE, Jacomb PA, Christensen H, Rodgers B, Pollitt P. "Mental health literacy": A survey of the public's ability to recognise mental disorders and their beliefs about the effectiveness of treatment. Medical Journal of Australia. 1997;166(4):182-6.

32. Pinfold V, Toulmin H, Thornicroft G, Huxley P, Farmer P, Graham T. Reducing psychiatric stigma and discrimination: evaluation of educational interventions in UK secondary schools. British Journal of Psychiatry. 2003;182:342-6.

33. Owen PR. Portrayals of Schizophrenia by Entertainment Media: A Content Analysis of Contemporary Movies. Psychiatric Services. 2012;63(7):655-9.

34. Weist MD, Murray M. Advancing school mental health promotion globally. Advances in School Mental Health Promotion. 2008;1(sup1):2-12.

35. Alonso J, Lépine J-P. Overview of key data from the European Study of the Epidemiology of Mental Disorders (ESEMeD). Journal of Clinical Psychiatry. 2007.

36. Yamaguchi S, Mino Y, Uddin S. Strategies and future attempts to reduce stigmatization and increase awareness of mental health problems among young people: A narrative review of educational interventions. Psychiatry and Clinical Neurosciences. 2011;65(5):405-15.

37. Moffitt T, Caspi A, Taylor A, Kokaua J, Milne B, Polanczyk G, et al. How common are common mental disorders? Evidence that lifetime prevalence rates are doubled by prospective versus retrospective ascertainment. Psychological Medicine. 2010;40(6):899-909.

38. Angermeyer MC, Holzinger A, Carta MG, Schomerus G. Biogenetic explanations and public acceptance of mental illness: systematic review of population studies. British Journal of Psychiatry. 2011;199(5):367-72.

39. Schomerus G, Schwahn C, Holzinger A, Corrigan P, Grabe H, Carta M, et al. Evolution of public attitudes about mental illness: a systematic review and meta-analysis. Acta Psychiatrica Scandinavica. 2012;125(6):440-52.

40. Kvaale EP, Haslam N, Gottdiener WH. The 'side effects' of medicalization: A meta-analytic review of how biogenetic explanations affect stigma. Clinical Psychology Review. 2013;33(6):782-94. 


\section{TABLES}

Table 1; Interview Schedule

\section{Focal points for group interviews:}

Current perception of mental health, e.g.

- What do the words 'mental health' make you think about?

- What do you think mental health means?

- Prompts include; what was the first thing you thought of? Where do you think your ideas come from? What helped you develop your understanding?

Past perception of mental health and development of mental health framework, e.g.

- When did you first hear about or think about mental health?

- Do you have enough information about mental health?

- Where can you get information about mental health?

- Prompts include; what would you like to know about mental health? Have you been taught anything in school? What about information on stress/bullying/exams?

Mental health in young people, e.g.

- What sorts of difficulties or problems do people your age face?

- What do people your age do if they have difficult feelings or problems?

- If you were worried about a friend, and thought they might have a mental health problem, what would you do?

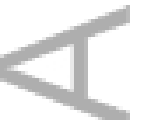

Table 2: Demographic characteristics of schools

\begin{tabular}{cccccc}
\hline School Type & Pupils with & Pupils with & & Ethnicity* \\
& English second & free school & South & White & Blac \\
& language* & meals* & Asian & k \\
\hline
\end{tabular}




\begin{tabular}{|c|c|c|c|c|c|c|c|}
\hline 1 & Girls only grammar school & $23 \%$ & $6 \%$ & $45 \%$ & $35 \%$ & $10 \%$ & $10 \%$ \\
\hline 2 & Boys only comprehensive & $26 \%$ & $30 \%$ & $35 \%$ & $47 \%$ & $6 \%$ & $12 \%$ \\
\hline
\end{tabular}

$3 \quad$ Boys only independent

Data not available

school

\begin{tabular}{|c|c|c|c|c|c|c|c|}
\hline 4 & Mixed grammar school & $15 \%$ & $2 \%$ & $16 \%$ & $70 \%$ & $1 \%$ & $13 \%$ \\
\hline 5 & $\begin{array}{l}\text { Mixed comprehensive } \\
\text { school }\end{array}$ & $54 \%$ & $42 \%$ & $45 \%$ & $26 \%$ & $12 \%$ & $17 \%$ \\
\hline 6 & Mixed sixth form college & & & vai & & & \\
\hline
\end{tabular}

*Data available from Birmingham City Council, accessed 2009

Table 3; Ice Breaker Games

Ice Breaker Games: Games lasted for approximately 10 minutes prior to the start of the interview schedule. Participants were encouraged by the researcher to elaborate on their answers and to discuss questions amongst themselves, to encourage a group interview dynamic.

1. 'Would you rather...' game. Questions include:

- Would you rather be invisible or able to read minds?

- Would you rather wrestle a lion or fight a shark?

- Would you rather be stranded on a deserted island alone or with someone you don't like?

2. Throw a dice, answer a question game. Participant roles a dice and then answers the corresponding question number from a sheet. Questions include:

- If you had a time machine that would work only once, what point in the future or in history would you

visit?

- What's the weirdest thing you've ever eaten?

- Who's your favourite cartoon character, and why?

Table 4: Characteristics of group interviews

\begin{tabular}{llll}
\hline Group Interview & Number in & Age / gender & Location \\
number & group interview & & \\
\hline G1 & 5 & $11-12 /$ female & On school premises in an empty \\
G2 & 5 & & classroom
\end{tabular}




\begin{tabular}{llll}
\hline G3 & 4 & $11-12 /$ male & On school premises in an empty \\
G4 & 5 & & classroom \\
\hline G6 & 5 & & \\
\hline G7 & 4 & $13-14 /$ female & After school hours in a participant's home \\
\hline G8 & 4 & $15-16 /$ male & After school hours in a participant's home \\
\hline G9 & 3 & $16-18 /$ male & In a meeting room, as part of a school \\
\hline G10 & 3 & $16-18 /$ female & In a meeting room, as part of a school \\
G12 & 3 & & \\
\hline
\end{tabular}

Table 5: Quotes illustrating each theme

Stereotypes

and Extremes

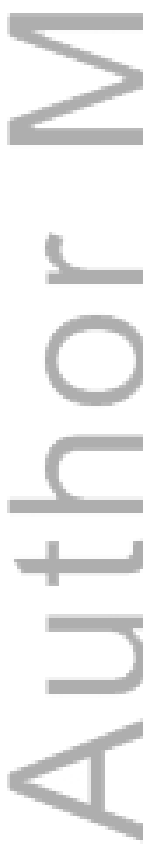

Danielle: last summer we were like walking down this road and then this like guy

Jenny: that was scary

Danielle: I think he was like drunk but also he seemed a bit strange

$\mathrm{KC}$ : yeah

Danielle: like, talking to himself and then he started

Jenny: screaming

Aminah: screaming

Danielle: like screaming at us 


\section{KC: yeah}

Danielle: and then that kind of doesn't help like our view on mental people cos like when you see someone in the street you like kind of like walk away from them quick

G6 13 -14 year old females

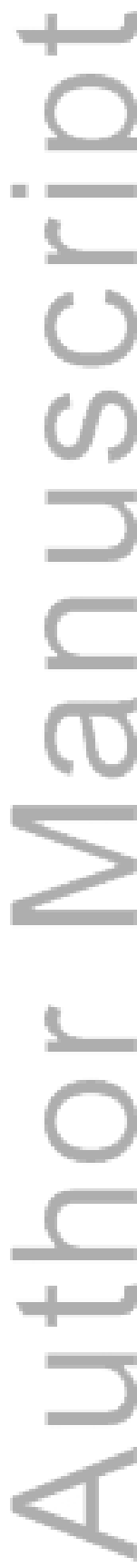

Amy: if someone had mental health problems I think it's a bit like sad because in films people portray it as someone whose gone crazy or something whereas if you actually had them yourself you may not actually be like that at all

G1 11-12 year old females

Mia: I think I first heard it when erm, erm like an animation came up on TV and er like it was about erm, loads of years ago but erm, but it was like a rabbit getting like really angry, I think it was buggs bunny I don't know why but um I thought that he like had mental illness, but I'm not being mean

KC: No no that's not mean

Mia: Yeah and um I thought that was kind of scary because they really freaked me out when I watched it

Katie: What kind of things made you think he had a mental illness?

Mia: Um his eyes just went really weird and a bit of like you could see his veins and stuff, and he went really crazy so... that just kind of scared me

G2 11-12 year old females

Jon: That always, like, makes it worse, for like for people who do have mental health problems, because all the news that you see is, like, bad.

Eli: Yeah. The only contact people really have is with is with the criminals. Seeing criminals, like, gives, I don't know, a bad reputation

G7 15-16 year old males

KC: Was there anything that made you think differently to the way you had before?

Jess: Erm I think personal experiences, because my mum's friend's got bi-polar and I thought

all schizophrenics and people with bi-polar are gonna be absolutely mental, but I think my 
opinion changed

G12 16-18 year old females

Debbie: I think it's good to have really good mental health but everyone has traits of something. Like everyone's got a little bit of OCD or something. Like everyone's got little traits of things. I don't think everyone is completely perfect. I think everyone's got a little bit of something mentally maybe, a little bit of, but I think when it spirals out of control, when it takes over their life so much that it becomes like a big problem.

G10 16-18 year old females

Ryan: They can say “why have you got mental problems”. They can't help it bla bla bla. If you take the mick out of them, then how do you know, how do you know you might not get mental problems when you're older.

$\mathrm{KC}: \mathrm{mmm}$

Si: Yeah but kids aren't like that in this school are they?

Ryan: Yeah but that's this school. What about other schools?

KC: Do you think kids in other schools might have mental health problems?

Ryan: Yeah loads of kids, all around the world.

G4 11-12 year old males

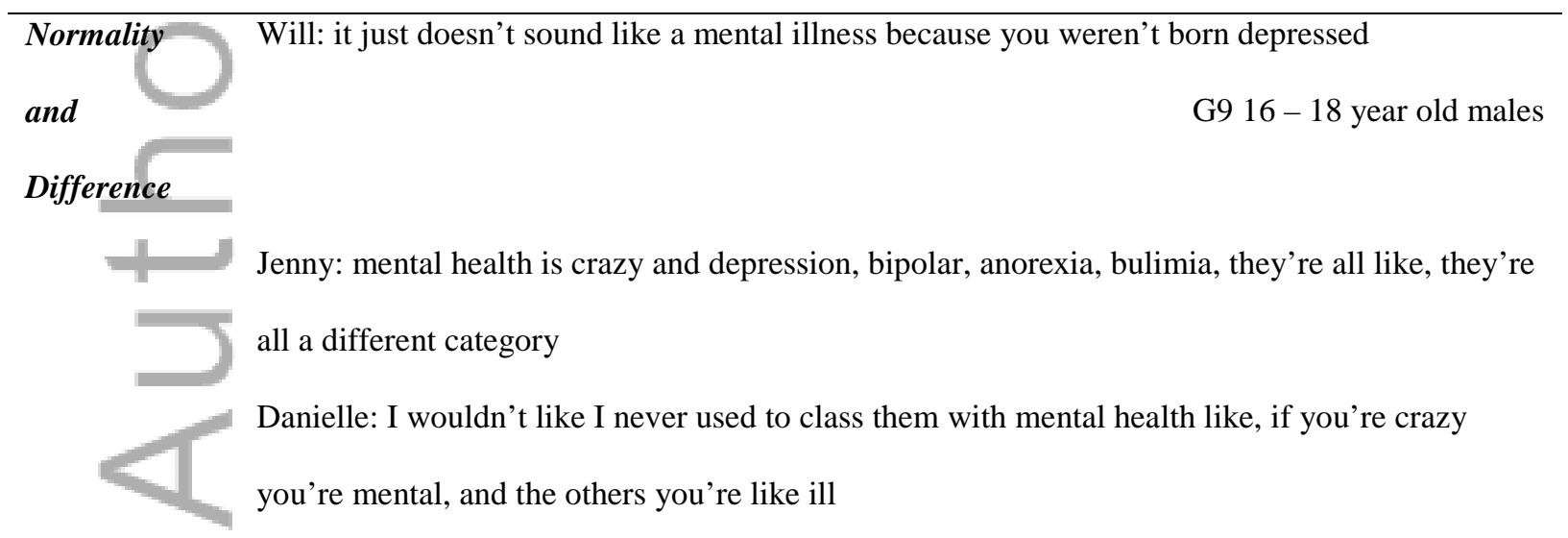

G6 13-14 year old females

Fear Rupa: the way she was talking as well like she was going to do something like she was going to
overdose again or something like that and it was really scary because it was like what, like I
can't sit in class and just think she will be okay because she is gonna be alone at home she could


do anything

G11 16-18 year old females

Jessica: I mean, obviously you're always a bit nervous about like things that do happen to someone and you don't want them to happen to you, but at the same time they don't scare me as much because I realise that they can be sorted out and, and so they don't seem as scary, I suppose.

G2 11-12 year old females

Kareem: he was telling me about times where he's feeling suicidal and he was thinking about times when he wanted to cut himself and when he wanted to hit people, even if they were boys or girls... Um, so... I guess I just, well, I kind of, like I did feel kind of, erm, satisfied that I was actually able to have a conversation with him.

G7 15-16 year old males 


\section{University Library}

\section{- M M N E R VA A gateway to Melbourne's research publications}

Minerva Access is the Institutional Repository of The University of Melbourne

Author/s:

Chisholm, K;Patterson, P;Greenfield, S;Turner, E;Birchwood, M

Title:

Adolescent construction of mental illness: implication for engagement and treatment

Date:

2018-08-01

Citation:

Chisholm, K., Patterson, P., Greenfield, S., Turner, E. \& Birchwood, M. (2018). Adolescent construction of mental illness: implication for engagement and treatment. EARLY

INTERVENTION IN PSYCHIATRY, 12 (4), pp.626-636. https://doi.org/10.1111/eip.12347.

Persistent Link:

http://hdl.handle.net/11343/261114 